Nama $\quad: \quad$ Jordhie Tanarubun

Nrp $\quad$ : 130117126

\begin{abstract}
Abstrak
Setiap organisasi selalu berusaha untuk meningkatkan kinerja nya, dalam meningkatkan kinerjanya ada beberapa standar yang telah dibentuk sebagai pedoman dalam mencapai tujuan tersebut. Setelah standar tersebut ditetapkan maka kinerja perusahaan dapat menjadi lebih baik, selain itu adapun beberapa hal yang dapat mempengaruhi kinerja perusahaan seperti pengaruh media sosial dan pengaruh lingkungan kerja. Dalam mengukur kinerja perusahaan maka dapat menggunakan beberapa metode, salah satunya menggunakan Social Return On Investment (SROI) ukuran kinerja non-keuangan yang digunakan oleh sebuah organisasi (Pratono S. a., 2017).
\end{abstract}

\title{
Firm Performance
}

Sebuah organisasi dapat mengukur keberhasilannya kinerja menggunakan beberapa metode baik secara keuangan maupun non-keuangan. Salah satu metode non keuangan yang digunakan adalah SROI. SROI (Social Return On Investment) merupakan sebuah pendekatan dalam memahami dan mengelola dampak atas nilai sosial (social value), ekonomi, dan lingkungan yang diciptakan dari suatu kegiatan atau organisasi, SROI menyediakan kerangka kerja dalam mengukur dampak sosial dari suatu komunitas program pembangunan dengan memasukkan sosial, lingkungan dan ekonomi biaya dan manfaat (Pratono, Suyanto, Marciano, \& Zurbügg, 2017). Analisis SROI berdasarkan pada asumsi, yang berhubungan dengan dampak, penilaian hasil, atribusi dan penurunan. Ada varians besar dalam asumsi dan masukan dalam banyak analisis SROI, dan penerapan memperkenalkan unsur subjektivitas yang cukup dapat membuat perbandingan angka SROI bermasalah (Pathik \& Dattani, 2014)

Penilaian kinerja sebuah organisasi tidak hanya dilakukan terhadap perusahaan besar, namun hal ini juga dapat dilakukan pada usaha kecil menengah. Beberapa penelitian mengenai kinerja usaha kecil dan mikro menggunakan pendekatan subyektif (Pratono, 2016). Seperti yang tercantum dalam peraturan daerah UU No 20/2008 UKM dibagi menjadi 3 kelompok yaitu Usaha mikro memiliki kriteria dengan penjualan kurang dari Rp300 juta dan aset kurang dari Rp50 juta. Bisnis kecil adalah perusahaan dengan aset antara Rp50 juta dan 
500.000 .000 serta penjualan antara Rp300 juta dan Rp 2,5 miliar per tahun, sementara perusahaan menengah adalah perusahaan dengan penjualan tahunan dari 2.500.000.000 untuk Rp50 milyar. Kinerja dari sebuah UKM dipengaruhi oleh perkembangan teknologi informasi, IT memberikan tantangan tersendiri bagi kinerja UKM. Turbulensi merupakan proses yang mengubah dampak variabel independen pada FP dalam teori kontingensi (Pratono, 2016). UKM yang lebih besar dapat meningkatkan kinerjanya sesuai dengan kondisi yang sedang dihadapi.

Banyak perusahaan telah menerapkan standar atau alat dalam mengukur kinerja perusahaannya agar tetap bersaing dengan perusahaan lainnya. Sebuah perusahaan harus siap menghadapi berbagai macam kondisi sehingga dapat bertahan. Oleh karena itu sebuah perusahaan harus mengukur kinerjanya sehingga dapat terus berkembang. Pengukuran kinerja perusahaan dapat dilihat dari tingkat kompentensi dan kepimimpinan serta motivasi yang diberikan oleh pimpinan perusahaan (Machmud \& Sidharta, 2016)), hal ini dilakukan dengan melihat motivasi kerja karyawan agar dapat mencapai kinerja yang maksimal, selain itu juga kinerja perusahaan dapat diukur dengan Balanced Scorecard, (Kaplan \& Norton, 2000) menyatakan Balanced Scorecard adalah sistem pengukuran yang menyeimbangkan alat ukur lama yang berdimensi pada aspek finansial dengan dimensi-dimensi yang baru yaitu pada aspek non finansial, BSC adalah model pengukuran kinerja bisnis yang tidak hanya mengukur kinerja organisasi bisnis namun juga organisasi sosial. Dengan adanya perbedaanperbedaan antara organisasi bisnis dan publik, maka Balanced Scorecard harus dimodifikasikan terlebih dahulu agar sesuai dengan kebutuhan organisasi publik (Rohm 2003).

\section{Entrepreneurial Orientation}

EO merupakan orientasi strategis tingkat perusahaan yang melakukan praktik pembuatan strategi organisasi, filosofi manajerial, serta perilaku perusahaan yang bersifat kewirausahaan. Orientasi kewirausahaan awalnya melibatkan proses pembuatan strategi serta mewakili kebijakan dan praktik yang membentuk dasar bagi tindakan dan keputusan dalam berwirausaha (Amie Kusumawardhani, 2009) , George dan Marino (2011) menjelaskan bahwa orientasi kewirausahaan diciptakan oleh dimensi, dan bahwa dimensi tidak menjadi manifestasi atau perwujudan dari kewirausahaan dengan orientasi membangun.

Investasi sumber daya alam yang mereka lakukan dalam membentuk usaha baru, tidak 
hanya mendapatkan manfaat moneter dari keputusan investasi tetapi juga mendapatkan utilitas dari otonomi kerja, EO dapat menjadi prediktor kinerja perusahaan dengan menganalisis faktor-faktor yang ada sehingga dapat menentukan orientasi perusahaan kedepannya (Rauch, Wiklund, Lumpkin, \& Frese, 2009), dengan adanya EO tidak dapat meningkatkan kinerja perusahaan, bahkan EO terkadang dapat merugikan perusahaan, jika situasi dalam perusahaan tidak sesuai dengan penerapan EO, namun terkadang ada perusahaan yang tetap berani mengambil risiko walaupun tidak selalu mampu menghasilkan kinerja yang baik (Pratono, 2018).

Studi baru-baru ini telah diperluas menjadi orientasi kewirausahaan hijau, yang menyoroti kepemimpinan teknologi hijau, produk hijau, teknik administrasi hijau, dan teknologi operasi hijau (Pratono, Darmasetiawan, \& Jeong, 2019), dengan adanya EO green dan dikaitkan dengan market oranisasi diharapkan dapat menciptakan keunggulan kompetitif yang terus berkelanjutan dan untuk mencapai kinerja yang diharapkan, sangat penting bagi perusahaan untuk mengadopsi otonomi kewirausahaan di mekanisme penetapan harga, yang melibatkan penyesuaian sendiri parameter harga untuk mempertimbangkan keduanya persyaratan aplikasi dan layanan pengguna

\section{Pengaruh Lingkungan Kerja Terhadap Peningkatan Kinerja Perusahaan}

Memahami pentingnya SDM merupakan tugas wajib sebuah perusahaan agar dapat tercipta sebuah sistem pengelolaan SDM yang akan meningkatkan kualitas kinerja karyawan, peningkatan kualitas kinerja karyawan diharapkan dapat mampu meningkatkan kinerja perusahaan. Salah satu langkah yang dapat dilakukan perusahaan dalam meningkatkan kinerja perusahaan yaitu dengan menciptakan lingkungan kerja yang ideal, baik lingkungan kerja fisik maupun lingkungan kerja non-fisik, menurut Musriha (2011), bahwa lingkungan kerja memiliki dampak positif terhadap kinerja karyawan. Menurut Noah dan Steve (2012), lingkungan kerja adalah keseluruhan hubungan yang terjadi dengan karyawan di tempat kerja. Segala sesuatu yang berada di tempat kerja merupakan lingkungan kerja.

Lingkungan kerja yang nyaman menyebabkan kinerja karyawan dalam bekerja meningkat, lingkungan kerja yang nyaman, baik lingkungan fisik maupun non fisik dapat secara tidak langsung memberikan dampak terhadap peningkatan prestasi kerja karyawan. Sehingga tercipta hubungan positif antara lingkungan kerja dan kinerja karyawan. 
Menurut Sedarmayanti (2001) dalam Hidayat (2015, p. 79) menyatakan ada beberapa faktor lingkungan kerja yang harus diperhatikan. Faktor lingkungan kerja fisik, meliputi faktor kebersihan, faktor penerangan, faktor pertukaran udara, faktor kebisingan, faktor keamanan. Dan lingkungan kerja non fisik yang meliputi hubungan kerja sama antara atasan dan bawahan. Agar terciptanya lingkungan non fisik yang baik perusahaan perlu membuat sebuah kegiatan atau program bulanan yang mengumpulkan atasan dan karyawan sehingga dapat tercipta hubungan baik dalam perusahaan, baik untuk atasan dan karyawan maupun karyawan-karyawan, hal ini diharapkan dapat meningkatkan kinerja karyawan yang kemudian berdampak langsung terhadap meningkatnya kinerja perusahaan.

\section{Kesimpulan}

Lingkungan kerja adalah salah satu faktor pendukung dalam perusahaan yang mampu meningkatkan kinerja karyawan, oleh karena itu perlu adanya manajemen perusahaan yang baik dalam mengatur lingkungan kerja. Lingkungan kerja tersebut bukan hanya lingkungan kerja fisik, tetapi juga non fisik, hal ini diharapkan agar terciptanya hubungan yang baik antara pimpinan perusahaan dengan karyawan. Terbentuknya lingkungan kerja yang nyaman bagi karyawan menyebabkan meningkatnya kinerja karyawan yang kemudian sejalan dengan meningkatnya kinerja perusahaan.

\section{Bibliografi}

Kaplan, \& Norton. (2000). The Strategy-Focused Organization: How Balanced Scorecard Companies Thrive in the New Business Environment. 29-64.

Machmud, \& Sidharta. (2016). Entrepreneurial Motivation and Business Performance of SMEs in the SUCI Clothing Center, Bandung, Indonesia. 63-78.

Pathik, \& Dattani. (2014). Social return on investment: three technical challenges. Social Enterprise Journal.

Pratono. (2016). Strategic orientation and information technological turbulence: Contingency perspective in SMEs . emeraldinsight, 377. 
Pratono, A. H., Suyanto, Marciano, D., \& Zurbügg, C. (2017). Social return on investment for community-based enterprise in Surabaya City. The Hong Kong Journal of Social Work, 51(01n02), 93-114.

Pratono, A. H. (2016). Strategic orientation and information technological turbulence: Contingency perspective in SMEs. Business Process Management Journal, 22(2).

Amie Kusumawardhani, G. M. (2009). Framework of entrepreneurial orientation and networking: a study of SMEs performance in a developing country.

George, B. a. (2011). The epistemology of entrepreneurial orientation: conceptual formation, modeling, and operationalization”, Entrepreneurship Theory and Practice.

Rauch, A., Wiklund, J., Lumpkin, G., \& Frese, M. (2009). Entrepreneurial Orientation and Business Performance: Assessment of Past Research and Suggestions for the Future.

Pratono, A. H. (2018). Does firm performance increase with risk-taking behavior under information technological turbulenc? Empirical evidence from Indonesian SMEs. The journal of risk finance, 19(4), 361-378.

Pratono, A., Darmasetiawan, N., \& Jeong, B. (2019). Achieve sustainable competitive advantage through green entrepreneurial orientation and market orientation: The role of inter-organizational learning.

Musriha. (2011). Influences of Work Behavior, Work Environment, and Motivation in Clove Cigarette Factories in Kudus, Indonesia. Academic Research International 1(3), 303 314.

Noah, Y. \& Steve, M. (2012). Work Environment and Job Attitude Among Employees in A Nigerian Work Organization. Journal of Sustainable Society 1(2), 36- 43.

Hidayat, C.N. (2015). Pengaruh Lingkungan Kerja dan Motivasi Kerja Terhadap Kinerja Karyawan Kantor PT. Keramik Diamond Industries. AGORA 3(2), 78-83 . 